\title{
Body mass index as a classifier to predict biochemical recurrence after radical prostatectomy in patients with lower prostate-specific antigen levels
}

\author{
KEISUKE GOTO $^{1}$, HIROTAKA NAGAMATSU ${ }^{1}$, JUN TEISHIMA ${ }^{1}$, YUKI KOHADA ${ }^{1}$, \\ SHINSUKE FUJII ${ }^{1}$, YOSHIMASA KURIMURA ${ }^{1}$, KOJI MITA $^{2}$, MASANOBU SHIGETA ${ }^{3}$, \\ SATOSHI MARUYAMA ${ }^{4}$, YOJI INOUE ${ }^{5}$, MITSURU NAKAHARA ${ }^{6}$ and AKIO MATSUBARA ${ }^{1}$
}

\author{
${ }^{1}$ Department of Urology, Hiroshima University Institute of Biomedical and Health Sciences, Hiroshima 734-8551; \\ ${ }^{2}$ Department of Urology, Hiroshima City Asa Hospital, Hiroshima 731-0293; ${ }^{3}$ Department of Urology, Kure Medical Center, \\ Chugoku Cancer Center, Kure, Hiroshima 737-0023; ${ }^{4}$ Department of Urology, Hiroshima General Hospital, \\ Hatsukaichi, Hiroshima 738-8503; ${ }^{5}$ Department of Urology, Mazda Hospital, Fuchu, Hiroshima 735-8585; \\ ${ }^{6}$ Department of Urology, Hiroshima Prefectural Hospital, Hiroshima 734-8530, Japan
}

Received October 15, 2016; Accepted January 10, 2017

DOI: $10.3892 / \mathrm{mco} .2017 .1223$

\begin{abstract}
Prostate cancer, one of the most common malignant tumors among men, is closely associated with obesity and, thus far, several studies have suggested the association between obesity and aggressive pathological characteristics in the United States. However, the effect of obesity on prostate cancer mortality is controversial, and it remains unclear whether obesity contributes to the aggressiveness of prostate cancer in Asian patients. The aim of the present study was to investigate the association between body mass index (BMI) and the clinicopathological characteristics of prostate cancer in 2,003 Japanese patients who underwent radical prostatectomy. There was a significant association between higher BMI and higher Gleason score (GS). The multivariate analysis also revealed that BMI was an independent indicator for GS $\geq 8$ at surgery. Moreover, among patients with lower prostate-specific antigen levels, biochemical recurrence-free survival was significantly worse in those with higher BMI. These results suggest that BMI may be a classifier for predicting adverse pathological findings and biochemical recurrence after radical prostatectomy in Japanese patients.
\end{abstract}

Correspondence to: Dr Jun Teishima, Department of Urology, Hiroshima University Institute of Biomedical and Health Sciences, 1-2-3 Kasumi, Minami-ku, Hiroshima 734-8551, Japan

E-mail: teishima@hiroshima-u.ac.jp

Key words: body mass index, obesity, prostate cancer, prostatectomy, prostate-specific antigen

\section{Introduction}

Prostate cancer (PCa) is the one of the most common malignant tumors among men in developed countries. Thus far, it has been suggested that diet and other environmental factors may affect the incidence of $\mathrm{PCa}$, as this incidence differs between countries and ethnic populations (1). In fact, migration studies showed an increased incidence of PCa in first-generation immigrants to the United States from Japan (2). These observations suggest that diet may play an important role in the incidence of $\mathrm{PCa}$ (3). In addition, several articles have reported various endogenous and exogenous factors that may contribute to PCa (4).

Obesity, which is generally measured by body mass index (BMI), is associated with increased mortality for all cancers combined (5). Obesity has also been suggested to be a risk factor in prostate cancer as well as breast and colon cancer $(6,7)$. However, the association of higher BMI with increased PCa incidence remains controversial (8). Previous studies presented evidence that obesity was associated with an increased risk of diagnosis of larger tumors, more aggressive disease and PCa-related mortality $(9,10)$, whereas other studies reported that obesity was not associated with aggressive pathological characteristics $(11,12)$. As regards biochemical recurrence, it has been reported that obese men are at increased risk of biochemical recurrence (13-17). Recently, obesity has become more prevalent among Asian countries, including Japan. Although obesity in Asian countries is less severe compared with that in western countries, certain studies have suggested an association between BMI and PCa, including pathological characteristics $(18,19)$. However, the effect of obesity on PCa-related mortality has been controversial, and it remains unclear whether obesity contributes to the aggressiveness of PCa in Asian patients $(20,21)$. The aim of the present study was to investigate the association between $\mathrm{BMI}$ and the clinicopathological characteristics of PCa, and determine whether obesity increases the risk of biochemical recurrence after radical prostatectomy (RP) in Japanese patients. 


\section{Patients and methods}

Patients. The subjects included 2003 Japanese patients with PCa who were treated with RP between 2005 and 2014 at Hiroshima University Hospital and affiliated hospitals. None of the patients had a history of preoperative hormonal or radiation therapy. Resection was considered to be curative in all patients based on node-negative pathology and a decrease in the serum level of prostate-specific antigen (PSA) postoperatively. The clinical records of these patients were retrospectively reviewed to investigate clinical information including age, serum PSA level, BMI and pathological characteristics. Staging was based on the 2005 TNM classification (https://www.nccn.org/professionals/physician_gls/pdf/prostate.pdf). Gleason score (GS) was assessed according to the International Society of Urological Pathology modified Gleason grading system (22). BMI was calculated as body weight divided by the square of the height $\left(\mathrm{kg} / \mathrm{m}^{2}\right)$ and was used to categorize patients into two groups according to the classification of obesity of the Japan Society for the Study of Obesity (http://www.jasso.or.jp/data/office/pdf/ guideline.pdf). Patients with BMI $<25 \mathrm{~kg} / \mathrm{m}^{2}$ were considered as the normoweight group, whereas those with BMI $\geq 25 \mathrm{~kg} / \mathrm{m}^{2}$ were considered as the overweight group. The associations between the two BMI groups and clinicopathological characteristics were examined. For the evaluation of prognosis, the serum PSA level was measured every 3 months after RP and biochemical recurrence was defined as an increase in the serum PSA level of $>0.2 \mathrm{ng} / \mathrm{ml}$ over two subsequent measurements.

Statistical analysis. Associations between BMI and clinicopathological characteristics were analyzed using the Chi-squared test. Age ( $\geq 70$ vs. $<70$ years) and serum PSA level ( $\geq 10$ vs. $<10 \mathrm{ng} / \mathrm{ml}$ ) were treated as categorical variables for all analyses. Logistic regression models were used to predict the risk for high-grade ( $G S \geq 8$ ) tumors at RP. Kaplan-Meier survival curves were constructed for the normoweight and overweight groups. Biochemical recurrence-free survival (bRFS) was compared between the normoweight and overweight groups and evaluated for statistical significance using a log-rank test. Univariate and multivariate Cox regression analyses were used to evaluate the associations between clinical covariates and bRFS. Hazard ratio and $95 \%$ confidence intervals were estimated with Cox proportional hazard models. All statistical tests were two-sided and a P-value of $<0.05$ was considered to indicate statistically significant differences. All statistical analyses were performed using JMP v10.0 software (SAS Institute, Cary, NC, USA) and the Kaplan-Meier survival curves were drawn using GraphPad Prizm v6.0 software (GraphPad Software Inc., San Diego, CA, USA).

\section{Results}

BMI is associated with higher GS. The median age of the patients was 68 years (range, 45-83 years), the PSA level was $7.50 \mathrm{ng} / \mathrm{ml}$ (range, $1-120 \mathrm{ng} / \mathrm{ml}$ ) and the BMI was $23.50 \mathrm{~kg} / \mathrm{m}^{2}$ (range, $15.9-38.0 \mathrm{~kg} / \mathrm{m}^{2}$ ). The pathological GS was $\geq 8$ in 537 patients $(26.8 \%)$, with extraprostatic extension (EPE) and a positive resection margin (RM) observed in 432 $(21.6 \%)$ and $554(27.6 \%)$ patients, respectively. Based on the
Table I. Associations between BMI and clinicopathological characteristics of prostate cancer.

\begin{tabular}{|c|c|c|c|}
\hline \multirow[b]{2}{*}{ Parameters } & \multicolumn{2}{|c|}{ BMI (kg/m²) } & \multirow[b]{2}{*}{ P-value } \\
\hline & $<25, \mathrm{n}(\%)$ & $\geq 25, \mathrm{n}(\%)$ & \\
\hline Operative approach & & & 0.2705 \\
\hline RRP & $533(73.6)$ & $191(26.4)$ & \\
\hline $\mathrm{RPP}$ & $95(70.9)$ & $39(29.1)$ & \\
\hline LRP & $587(69.4)$ & $259(30.6)$ & \\
\hline RALP & $219(73.2)$ & $80(26.8)$ & \\
\hline Age (years) & & & 0.1379 \\
\hline$<70$ & $836(72.9)$ & $311(27.1)$ & \\
\hline$\geq 70$ & $598(69.8)$ & $258(30.1)$ & \\
\hline PSA (ng/ml) & & & 0.4603 \\
\hline$<10$ & $943(71.1)$ & $384(28.9)$ & \\
\hline$\geq 10$ & $491(72.6)$ & $185(27.4)$ & \\
\hline pT stage & & & 0.2943 \\
\hline $\mathrm{T} 2$ & $1,120(72.6)$ & $432(27.8)$ & \\
\hline T3 & 314 (69.6) & $137(30.4)$ & \\
\hline GS & & & 0.0308 \\
\hline$\leq 7$ & $1,069(72.9)$ & $397(27.1)$ & \\
\hline$\geq 8$ & $365(68.0)$ & $172(32.0)$ & \\
\hline $\mathrm{EPE}$ & & & 0.2182 \\
\hline EPE0 & $1,135(72.3)$ & $436(27.8)$ & \\
\hline EPE1 & $299(69.2)$ & $133(30.8)$ & \\
\hline $\mathrm{RM}$ & & & 0.1999 \\
\hline RM0 & $1,049(72.4)$ & $400(27.6)$ & \\
\hline RM1 & $385(69.5)$ & $169(30.5)$ & \\
\hline
\end{tabular}

BMI, body mass index; LRP, laparoscopic radical prostatectomy; RALP, robot-assisted laparoscopic radical prostatectomy; RPP, retroperineal radical prostatectomy; RRP, retropubic radical prostatectomy; GS, Gleason score; EPE, extraprostatic extension; RM, resection margin

BMI distribution, 569 patients (28.4\%) comprised the overweight group (BMI $\geq 25 \mathrm{~kg} / \mathrm{m}^{2}$ ), and 1,434 patients $(71.6 \%)$ comprised the normoweight group (BMI $<25 \mathrm{~kg} / \mathrm{m}^{2}$ ). The BMI exhibited a normal distribution. Only 33 patients $(1.6 \%)$ had a BMI $>30 \mathrm{~kg} / \mathrm{m}^{2}$. When comparing the clinicopathological characteristics between the normoweight and overweight groups (Table I), no significant differences were observed in age ( $\geq 70$ years), PSA ( $\geq 10 \mathrm{ng} / \mathrm{ml})$, pathological T stage $(\geq \mathrm{T} 3)$, EPE and RM.

However, the number of patients with pathological GS $\geq 8$ was higher in the overweight group $(\mathrm{P}=0.0308$, Chi-squared test). Logistic regression analysis was next performed to evaluate whether BMI may be a predictor for PCa with higher GS (Table II). The univariate analysis revealed that age ( $\geq 70$ years), PSA ( $\geq 10 \mathrm{ng} / \mathrm{ml}$ ), GS at biopsy $(\geq 4+3)$ and BMI $\left(\geq 25 \mathrm{~kg} / \mathrm{m}^{2}\right.$ ) were significantly associated with GS $\geq 8$ at RP. In addition, a multivariate analysis including age, PSA, GS at biopsy and BMI also revealed that PSA, GS at biopsy and BMI were independent indicators for GS $\geq 8$ at RP. These results 
Table II. Univariate and multivariate logistic regression models to predict tumors with GS $\geq 8$.

\begin{tabular}{|c|c|c|c|c|c|c|}
\hline \multirow[b]{2}{*}{ Parameters } & \multicolumn{3}{|c|}{ Univariate analysis } & \multicolumn{3}{|c|}{ Multivariate analysis } \\
\hline & OR & $95 \% \mathrm{CI}$ & P-value & OR & $95 \% \mathrm{CI}$ & P-value \\
\hline \multicolumn{7}{|l|}{ Age (years) } \\
\hline$<70$ & 1 (Reference) & & & 1 (Reference) & & \\
\hline$\geq 70$ & 1.301 & $1.067-1.588$ & 0.0095 & 1.208 & $0.970-1.506$ & 0.0913 \\
\hline \multicolumn{7}{|l|}{ PSA (ng/ml) } \\
\hline$<10$ & 1 (Reference) & & & 1 (Reference) & & \\
\hline$\geq 10$ & 2.698 & $2.200-3.311$ & $<0.0001$ & 2.180 & $1.747-2.722$ & $<0.0001$ \\
\hline \multicolumn{7}{|c|}{ GS (at biopsy) } \\
\hline$\leq 3+4$ & 1 (Reference) & & & 1 (Reference) & & \\
\hline$\geq 4+3$ & 6.784 & $5.418-8.544$ & $<0.0001$ & 6.113 & $4.865-7.724$ & $<0.0001$ \\
\hline \multicolumn{7}{|c|}{ BMI $\left(\mathrm{kg} / \mathrm{m}^{2}\right)$} \\
\hline$<25$ & 1 (Reference) & & & 1 (Reference) & & \\
\hline$\geq 25$ & 1.269 & $1.022-1.571$ & 0.0308 & 1.291 & $1.016-1.638$ & 0.0364 \\
\hline
\end{tabular}

suggest that obesity may be associated with adverse pathological findings of $\mathrm{PCa}$.

BMI is a predictor of the prognosis of PCa at lower PSA levels. The median follow-up period of this study was 34 months (range, 0-108 months). Of the 2003 patients, 396 (19.8\%) experienced biochemical recurrence, including 283 of the 1,434 (19.7\%) in the normoweight group and 113 of the 569 (19.9\%) in the overweight group. Kaplan-Meier analysis was used to evaluate the association of BMI with biochemical recurrence. When evaluated in all 2003 cases, there was no significant difference between bRFS in the normoweight vs. the overweight group (Fig. 1A). In patients with lower PSA levels $(<10 \mathrm{ng} / \mathrm{ml})$, the overweight group exhibited a significantly worse prognosis compared with the normoweight group ( $\mathrm{P}=0.0179$, log-rank test, Fig. 1B). However, no significant difference was observed in patients with higher PSA levels (>10 ng/ml, Fig. 1C).

Univariate and multivariate Cox proportional hazards analyses were next performed to evaluate the role of BMI as a predictor of bRFS in patients with PSA $<10 \mathrm{ng} / \mathrm{ml}$ (Table III). The univariate analysis indicated that pathological stage T3, GS $\geq 8$, EPE1, RM1 and BMI $>25 \mathrm{~kg} / \mathrm{m}^{2}$ were significantly associated with bRFS, whereas age was not. The multivariate model, which included pT stage, GS, EPE, RM and BMI, revealed that BMI was not an independent predictor of $b R F S$, whereas pT3, GS $\geq 8$ and RM1 were.

\section{Discussion}

The association between BMI and the clinicopathological characteristics was investigated in 2003 Japanese patients with PCa who underwent RP. First, it was demonstrated that high BMI was associated with adverse pathological findings. These results, supported those of previous studies showing that obese men in the United States who underwent RP had higher-grade
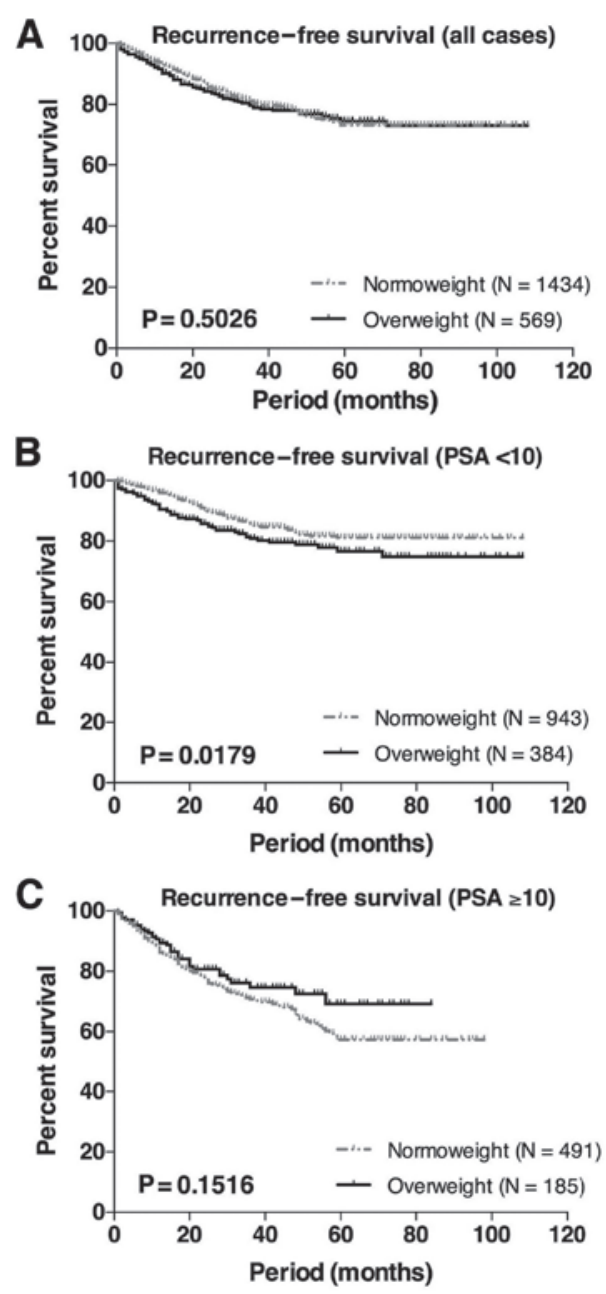

Figure 1. Biochemical recurrence-free survival after radical prostatectomy in (A) 2,003 patients with PCa, (B) 1,327 patients with serum PSA $<10 \mathrm{ng} / \mathrm{ml}$ and (C) 676 patiens with serum PSA $\geq 10 \mathrm{ng} / \mathrm{ml}$. Statistical significance was evaluated using the log-rank test. PCa, prostate cancer; PSA, prostate-specific antigen. 
Table III. Univariate and multivariate Cox proportional hazard models for biochemical recurrence after prostatectomy in patients with PSA $<10 \mathrm{ng} / \mathrm{ml}$.

\begin{tabular}{|c|c|c|c|c|c|c|}
\hline \multirow[b]{2}{*}{ Parameters } & \multicolumn{3}{|c|}{ Univariate analysis } & \multicolumn{3}{|c|}{ Multivariate analysis } \\
\hline & HR & $95 \% \mathrm{CI}$ & P-value & HR & $95 \% \mathrm{CI}$ & P-value \\
\hline Age (years) & & & 0.1715 & & & 0.1768 \\
\hline$<70$ & 1 (Reference) & & & 1 (Reference) & & \\
\hline$\geq 70$ & 1.224 & $0.916-1.631$ & & 1.222 & $0.913-1.631$ & \\
\hline pT stage & & & $<0.0001$ & & & 0.0330 \\
\hline $\mathrm{T} 2$ & 1 (Reference) & & & 1 (Reference) & & \\
\hline $\mathrm{T} 3$ & 3.866 & $2.872-5.174$ & & 2.273 & $1.070-4.528$ & \\
\hline GS & & & $<0.0001$ & & & $<0.0001$ \\
\hline$\leq 7$ & 1 (Reference) & & & 1 (Reference) & & \\
\hline$\geq 8$ & 3.461 & $2.585-4.617$ & & 2.433 & $1.791-3.291$ & \\
\hline EPE & & & $<0.0001$ & & & 0.9371 \\
\hline EPE0 & 1 (Reference) & & & 1 (Reference) & & \\
\hline EPE1 & 3.433 & $2.541-4.603$ & & 0.971 & $0.489-2.049$ & \\
\hline $\mathrm{RM}$ & & & $<0.0001$ & & & $<0.0001$ \\
\hline RM0 & 1 (Reference) & & & 1 (Reference) & & \\
\hline RM1 & 3.926 & $2.946-5.235$ & & 2.712 & $1.992-3.693$ & \\
\hline BMI $\left(\mathrm{kg} / \mathrm{m}^{2}\right)$ & & & 0.0309 & & & 0.4604 \\
\hline$<25$ & 1 (Reference) & & & 1 (Reference) & & \\
\hline$\geq 25$ & 1.400 & $1.032-1.882$ & & 1.122 & $0.824-1.515$ & \\
\hline
\end{tabular}

BMI, body mass index; CI, confidence interval; HR, hazard ratio; PSA, prostate-specific antigen; GS, Gleason score; EPE, extraprostatic extension; RM, resection margin.

and larger tumors (8,10,13-17). In Asian patients, the adverse pathological findings of PCa may be attributable to obesity according to previous reports $(18,19)$.

However, other reports have not demonstrated any association of obesity with the clinicopathological characteristics of PCa $(20,21)$. Such conflicting results may be explained by the different distribution of BMI among countries. As the obese (BMI $\geq 30 \mathrm{~kg} / \mathrm{m}^{2}$ ) population accounted for only $1-2 \%$ of the cases in reports from Asian countries, the cutoff for normal $\mathrm{BMI}$ is variably classified as 23.5 or $25.0 \mathrm{~kg} / \mathrm{m}^{2}$. In the present study, a significant association of BMI with GS was observed, whereas such an association was not observed for serum PSA level, pT stage, EPE and RM. These results may suggest that a higher BMI was associated with more aggressive phenotypes of $\mathrm{PCa}$.

Although there was no significant association between BMI and serum PSA level (Table I), the overweight group exhibited a greater risk of biochemical recurrence in patients with lower PSA levels (Fig. 1B). Indeed, previous studies reported that BMI is inversely associated with serum PSA levels $(23,24)$, and a higher BMI is associated with higher plasma volume (25). Thus, the reason why obese men have lower serum PSA concentrations may be explained by the hemodilution theory $(26,27)$. Therefore, it is possible that the serum PSA levels may be modified in the overweight group. However, in the multivariate analysis, BMI was not an independent predictor of biochemical recurrence. Recently, PSA mass, which was associated with visceral adipose tissue, was suggested to be a promising indicator for determining an absolute PSA level (28).

Previous studies have also demonstrated an association between obesity and the aggressiveness of PCa through various molecular mechanisms, including oxidative stress, endocrine activities, or other cytokine activities (29). It is known that adipose tissue secretes certain inflammatory cytokines, referred to as adipocytokines (30). In addition, we previously reported a positive correlation between the aggressiveness of PCa and fibroblast growth factor (FGF)-19, including the endocrine FGF subfamily that circulates in the serum and acts in an endocrine-like manner (31). Further investigations are required to elucidate the associations between BMI or obesity and PSA levels.

The present study had certain limitations. First, the median follow-up period for establishing biochemical recurrence after RP was relatively short. Second, this was a retrospective study that involved patients subjected to RP using different procedures by several surgeons, although the oncological outcomes of retropubic, retroperitoneal, laparoscopic and robot-assisted laparoscopic RP were comparable $(32,33)$. Third, we investigated whether obesity affects pathological findings and biological recurrence after RP using only preoperative BMI, as postoperative BMI values were not available. Although it remains unclear whether weight loss may help improve outcomes among patients already diagnosed with 
$\mathrm{PCa}$, further investigations are required to elucidate the role of BMI post-RP.

In summary, the results of the present study, including 2003 Japanese patients who underwent RP for PCa, provide evidence that a higher BMI may be associated with adverse pathological findings. Although BMI was not an independent predictor for bRFS after RP, BMI may be associated with more aggressive characteristics of $\mathrm{PCa}$.

\section{References}

1. Dunn JE: Cancer epidemiology in populations of the United States-with emphasis on Hawaii and California-and Japan. Cancer Res 35: 3240-3245, 1975.

2. Shimizu H, Ross RK, Bernstein L, Yatani R, Henderson BE and Mack TM: Cancers of the prostate and breast among Japanese and white immigrants in Los Angeles County. Br J Cancer 63: 963-966, 1991.

3. Park SY, Haiman CA, Cheng I, Park SL, Wilkens LR, Kolonel LN, Le Marchand L and Henderson BE: Racial/ethnic differences in lifestyle-related factors and prostate cancer risk: The multiethnic cohort study. Cancer Causes Control 26: 1507-1515, 2015.

4. Bostwick DG, Burke HB, Djakiew D, Euling S, Ho SM, Landolph J, Morrison H, Sonawane B, Shifflett T, Waters DJ and Timms B: Human prostate cancer risk factors. Cancer 101 (10 Suppl): S2371-S2490, 2004.

5. Calle EE, Rodriguez C, Walker-Thurmond $\mathrm{K}$ and Thun MJ: Overweight, obesity, and mortality from cancer in a prospectively studied cohort of U.S. adults. N Engl J Med 348: 1625-1638, 2003

6. Andersson SO, Wolk A, Bergström R, Adami HO, Engholm G, Englund A and Nyrén O: Body size and prostate cancer: A 20-year follow-up study among 135006 Swedish construction workers. J Natl Cancer Inst 89: 385-389, 1997.

7. Giovannucci E, Rimm EB, Liu Y, Leitzmann M, Wu K, Stampfer MJ and Willett WC: Body mass index and risk of prostate cancer in U.S. health professionals. J Natl Cancer Inst 95: 1240-1244, 2003.

8. Discacciati A, Orsini N and Wolk A: Body mass index and incidence of localized and advanced prostate cancer-a dose-response meta-analysis of prospective studies. Ann Oncol 23: 1665-1671, 2012.

9. Rodriguez C, Patel AV, Calle EE, Jacobs EJ, Chao A and Thun MJ: Body mass index, height, and prostate cancer mortality in two large cohorts of adult men in the United States. Cancer Epidemiol Biomarkers Prev 10: 345-353, 2001.

10. Freedland SJ, Bañez LL, Sun LL, Fitzsimons NJ and Moul JW: Obese men have higher-grade and larger tumors: An analysis of the duke prostate center database. Prostate Cancer Prostatic Dis 12: 259-263, 2009.

11. Chamie K, Oberfoell S, Kwan L, Labo J, Wei JT and Litwin MS: Body mass index and prostate cancer severity: Do obese men harbor more aggressive disease on prostate biopsy? Urology 81: 949-955, 2013

12. Tomaszewski JJ, Chen YF, Bertolet M, Ristau BT, Woldemichael E and Nelson JB: Obesity is not associated with aggressive pathologic features or biochemical recurrence after radical prostatectomy. Urology 81: 992-996, 2013.

13. Amling CL, Riffenburgh RH, Sun L, Moul JW, Lance RS, Kusuda L, Sexton WJ, Soderdahl DW, Donahue TF, Foley JP, et al: Pathologic variables and recurrence rates as related to obesity and race in men with prostate cancer undergoing radical prostatectomy. J Clin Oncol 22: 439-445, 2004.

14. Freedland SJ, Aronson WJ, Kane CJ, Presti C Jr, Amling CL, Elashoff D and Terris MK: Impact of obesity on biochemical control after radical prostatectomy for clinically localized prostate cancer: A report by the Shared Equal Access Regional Cancer Hospital database study group. J Clin Oncol ;22: 446-453, 2004.

15. Freedland SJ, Terris MK, Presti JC Jr, Amling CL, Kane CJ, Trock B and Aronson WJ; Search Database Study Group: Obesity and biochemical outcome following radical prostatectomy for organ confined disease with negative surgical margins. J Urol 172: 520-524, 2004.

16. Freedland SJ, Grubb KA, Yiu SK, Humphreys EB, Nielsen ME, Mangold LA, Isaacs WB and Partin AW: Obesity and risk of biochemical progression following radical prostatectomy at a tertiary care referral center. J Urol 174: 919-922, 2005.
17. Freedland SJ, Isaacs WB, Mangold LA, Yiu SK, Grubb KA, Partin AW, Epstein JI, Walsh PC and Platz EA: Stronger association between obesity and biochemical progression after radical prostatectomy among men treated in the last 10 years. Clin Cancer Res 11: 2883-2888, 2005.

18. Lee SE, Lee WK, Jeong MS, Abdullajanov M, Kim DS, Park HZ, Jeong SJ, Yoon CY, Byun SS, Choe G and Hong SK: Is body mass index associated with pathological outcomes after radical prostatectomy in Korean men? BJU Int 107: 1250-1255, 2011.

19. Bai PD, Hu MB, Xu H, Zhu WH, Hu JM, Yang T, Jiang HW and Ding Q: Body mass index is associated with higher Gleason score and biochemical recurrence risk following radical prostatectomy in Chinese men: A retrospective cohort study and meta analysis. World J Surg Oncol 13: 311, 2015.

20. Komaru A, Kamiya N, Suzuki H, Endo T, Takano M, Yano M, Kawamura K, Imamoto T and Ichikawa T: Implications of body mass index in Japanese patients with prostate cancer who had undergone radical prostatectomy. Jpn J Clin Oncol 40: 353-359, 2010.

21. Narita S, Mitsuzuka K, Yoneyama T, Tsuchiya N, Koie T, Kakoi N, Kawamura S, Kaiho Y, Ohyama C, Tochigi T, et al: Impact of body mass index on clinicopathological outcome and biochemical recurrence after radical prostatectomy. Prostate Cancer Prostatic Dis 16: 271-276, 2013.

22. Epstein JI, Egevad L, Amin MB, Delahunt B, Srigley JR and Humphrey PA; Grading Committee: The 2014 international society of urological pathology (ISUP) consensus conference on gleason grading of prostatic carcinoma: Definition of grading patterns and proposal for a new grading system. Am J Surg Pathol 40: 244-252, 2016

23. Baillargeon J, Pollock BH, Kristal AR, Bradshaw P, Hernandez J, Basler J, Higgins B, Lynch S, Rozanski T, Troyer D and Thompson I: The association of body mass index and prostate-specific antigen in a population-based study. Cancer 103: 1092-1095, 2005.

24. Werny DM, Thompson T, Saraiya M, Freedman D, Kottiri BJ, German RR and Wener M: Obesity is negatively associated with prostate-specific antigen in U.S. men, 2001-2004. Cancer Epidemiol Biomarkers Prev 16: 70-76, 2007.

25. Bañez LL, Hamilton RJ, Partin AW, Vollmer RT, Sun L, Rodriguez C, Wang Y, Terris MK, Aronson WJ, Presti $\mathrm{JC} \mathrm{Jr}$, et al: Obesity-related plasma hemodilution and PSA concentration among men with prostate cancer. JAMA 298: 2275-2280, 2007.

26. Rundle A, Richards C and Neugut AI: Body composition, abdominal fat distribution and prostate-specific antigen test results. Cancer Epidemiol Biomarkers Prev 18: 331-336, 2009.

27. Grubb RL III, Black A, Izmirlian G, Hickey TP, Pinsky PF, Mabie JE, Riley TL, Ragard LR, Prorok PC, Berg CD, et al: Serum prostate-specific antigen hemodilution among obese men undergoing screening in the prostate, lung, colorectal, and ovarian cancer screening trial. Cancer Epidemiol Biomarkers Prev 18: 748-751, 2009.

28. Park SG, Choi HC, Cho B, Kwon YM, Kwon HT and Park JH: Effect of central obesity on prostate specific antigen measured by computerized tomography: Related markers and prostate volume. J Urol 187: 1589-1593, 2012.

29. Buschemeyer WC III and Freedland SJ: Obesity and prostate cancer: Epidemiology and clinical implications. Eur Urol 52: 331-343, 2007.

30. Arisan ED, Arisan S, Atis G, Palavan-Unsal N and Ergenekon E: Serum adipocytokine levels in prostate cancer patients. Urol Int 82: 203-208, 2009.

31. Nagamatsu H, Teishima J, Goto K, Shikuma H, Kitano H, Shoji K, Inoue S and Matsubara A: FGF19 promotes progression of prostate cancer. Prostate 75: 1092-1101, 2015.

32. Salomon L, Levrel O, de la Taille A, Anastasiadis AG, Saint F, Zaki S, Vordos D, Cicco A, Olsson LE, Hoznek A, et al: Radical prostatectomy by the retropubic, perineal and laparoscopic approach: 12 years of experience in one center. Eur Urol 42: 104-111, 2002

33. Lim SK, Kim KH, Shin TY and Rha KH: Current status of robot-assisted laparoscopic radical prostatectomy: How does it compare with other surgical approaches? Int J Urol 20: 271-284, 2013. 